Guéguen, N., Martin, A., Silone, F \& Pascual, A (sous presse). Foot-in-the-Door Technique, Crime, and the Responsive Bystander: A Field Experiment. Crime Prevention and Community Safety.

\title{
The Foot-in-the-Door Technique, Crime, and the Responsive Bystander: A Field Experiment
}

\begin{abstract}
A bystander's reaction to a theft following a foot-in-the door (FITD) technique was observed in a field setting. An experiment was conducted in the pavement area of a bar where a first male confederate was seated alone with his suitcase on the ground. In the FITD condition, the confederate asked a participant for the time, thanked him/her, and left to go into the bar. In the control condition, no initial verbal contact was displayed, and the confederate just left to go into the bar. About 20 seconds after the first confederate had left to go into the bar, a second male confederate arrived, looked carefully around him, took the first confederate's suitcase, and then left the place. More participants intervened in the FITD condition to stop the theft $(84 \%)$ than in the control condition $(47 \%)$. Social responsibility activation was used to explain these results.
\end{abstract}

Keywords: Foot-in-the-door, theft, bystander, social responsibility

The effect of commitment on people's behavior in a problematic situation has been reported in several studies. In two field experiments, Moriarty (1975) demonstrated that more bystanders tried to stop a theft if they had previously shown commitment to the victim of the theft. In the first experiment, conducted on a beach, a first confederate (the victim) placed a blanket near a participant and turned on a portable radio. After 2 minutes, the victim left his blanket and spoke to the participant. In the commitment condition, he asked the participant to watch his things because he had to go up to the boardwalk for a few minutes, while in the no-commitment control condition, he asked the participant for a lighter. The victim then strolled away in the direction of the boardwalk and remained out of sight. One minute later, a second confederate (the thief) walked up to the victim's blanket, picked up the portable radio, and walked away in the opposite direction of the victim. The participants' reaction to the theft was the dependent variable measured in this experiment. In the commitment condition, $95 \%$ of the participants intervened to stop the theft while only $20 \%$ did so in the control no-commitment condition. A second experiment, where customers in a restaurant were or not committed by a female confederate to watch her suitcase, confirmed these results. In this experiment, $100 \%$ of the participants intervened when the theft occurred while only $13 \%$ did so in the control no-commitment condition.

The effect of commitment on the reaction to a crime has been reported in several other studies (Shaffer, Rogel, \& Hendrick, 1975; Harris \& Samerotte, 1976; Stewart \& Cannon, 1977; Schwarz, Jennings, Petrillo, \& Kidd, 1980). In all these studies, the effect-size of the effect of commitment on people's intervention was high.

\section{The Foot-in-the-Door Technique}

The purpose of the present study was to examine whether the effect of an interaction between the victim and the participant could exert the same commitment effect. In the studies previously mentioned, the control condition could be considered as a foot-in-the-door condition. The foot-in-the-door technique involves first making someone an easy request, then making the same individual a second, more expensive request. Findings have shown that greater compliance to the second request is observed than if this latter request had been directly addressed to the participant. In the seminal work on this technique, Freedman and Fraser (1966) reported that more housewives accepted to allow a team of five or six investigators to come to their homes for 2 hours to make an inventory of all the household products they used if, 3 days previously, the women were asked to fill out a short questionnaire containing eight questions concerning their household products. 
Various meta-analyses of numerous studies on this technique have shown its effects on compliance (Beaman, Cole, Preston, Klentz, \& Merhrkens-Steblay, 1983; Dillard, Hunter, \& Burgoon, 1984; Fern, Monroe, \& Avila, 1986; Burger, 1999; Pascual \& Guéguen, 2005). It is well-known that this technique is particularly effective for influencing people to respond positively to various pro-social requests. Examples of such requests include giving someone a dime (Harris, 1972; Guéguen \& Fischer-Lokou, 1999), answering a questionnaire (Hornik, Zaig, \& Shadmon, 1991), and persuading students to take a card designating them as organ donors (Carduci, Deuser, Bauer, Large, \& Ramaekers, 1989). It has also been found that the FITD is an effective method to increase compliance in phone interactions (Goldman, Creason \& McCall, 1981) or in computer-mediated communication (Guéguen \& Jacob, 2001).

Studies have also indicated that the effectiveness of the FITD technique is not limited to pro-social requests. FITD has been shown to be effective in decreasing people's energy consumption at home (Katzev \& Johnson, 1983) or increasing the number of owners who accepted to record a month's worth of their household waste on a form (Guéguen, Meineri, Martin, \& Grandjean, 2010). Dolin and Booth-Butterfield (1995) found that adult women assigned to an FITD request during a shopping mall health fair were more willing to accept a request to schedule a gynecological examination. Guéguen, Marchand, Lourel, and Pascual (2008) reported that the FITD was effective in a dating context. In their study, women who were first solicited to give directions to a male confederate or to give him a light for his cigarette were more willing to accept to have a drink several seconds later. Joule (1987) also reported the results of a study that used the FITD technique in a smoking cessation program.

In the literature, the foot-in-the-door effect is explained in two ways. The first and more frequent explanation is the self-perception theory (Freedman \& Fraser, 1966). This theory posits that the preliminary request makes participants feel that they are helping and caring for other people. Once this perception is activated, it promotes compliance with the second request. The explanation based on self-perception is perhaps readily explained by the fact that many of the requests tested were pro-social in nature. Other scientists explain the effect of FITD with the help of the commitment theory (Kiesler, 1971; Joule, 1987; Cialdini, 2008). When accepting to comply with an initial request, an individual is committed to complying with a later request in order to act consistently.

When comparing the literature on the FITD technique and the literature examining the effect of commitment in a theft situation, it is worth noting that in Moriarty's (1975) study, the participants in the control condition were not committed to watch the confederate's things. A first request was used (asking the participant for a lighter) to eliminate a possible confounding effect between the verbal interaction and the commitment. However, asking someone for a lighter, the time, or making any other innocuous request can be considered as the first request in the FITD technique. Harris (1972) and Guéguen and Fischer-Lokou (1999) first asked participants for the time and then asked the latter to give them a dime. In both studies, more participants gave money after being asked for the time than participants who were asked for money directly. Thus, the control condition in Moriarty's (1975) study could be considered to be a FITD condition rather than a real control condition.

In this study, we decided to examine the effect of the FITD in reaction to a theft, which could be considered a high-cost request and a more problematic one than the requests usually employed in previous studies on this topic. A first confederate asked or not a participant for the time and left the place, leaving his suitcase behind. A second confederate arrived and stole the suitcase. In light of the positive effect of the FITD on compliance, as reported previously, it was hypothesized that participants would intervene more often in the FITD condition than in the control condition.

\section{Method}

\section{Participants}

The participants were 76 adult individuals (44 males and 32 females) randomly assigned to two groups. All the participants were Caucasian and were between 20 and 30 years of age. They were all tested while they were seated alone in the pavement area of a bar in the center of a medium-sized town (more than 70,000 inhabitants) located in western France, on the Atlantic coast of Brittany.

\section{Procedure}

A 20-year-old man acted as the first confederate (the victim) in this study while another 20-year-old man acted as the second confederate (the thief). The first confederate arrived, sat at an available table near 
another table occupied by someone who was alone, and placed a suitcase on the ground. The confederate was instructed not to select the participant but to act with the participant who was sitting alone and at the table closest to his. He was instructed to sit without making any verbal or nonverbal contact with the participant. After one minute, the confederate stood up and, with a smile, asked the participant for the time. After receiving the response, the confederate thanked the participant and went into the bar, leaving his suitcase behind. In the control condition, the confederate waited one minute, stood up, and went into the bar without making any verbal or nonverbal contact with the participant.

The confederates were instructed to test a participant in one of the two experimental conditions according to a prearranged order obtained by random allocation software. In both experimental conditions, after 20 seconds, the second confederate arrived near the table where the first confederate had been sitting and began to look around and inside the bar for about 10 seconds. Then, he grabbed the suitcase of the first confederate and began to walk. At that point, the participant's behavior was assessed. If the participant said nothing, his/her behavior was classified as a non-intervention behavior. The behavior was classified as an intervention behavior if the participant said that the first confederate would return soon, if he/she said that the suitcase was not the thief's, or if he/she intervened physically to stop the confederate-thief.

\section{Results}

The number of male and female participants who intervened in both experimental conditions is shown in Table 1.

Table 1

Frequency of participants who intervened to stop the theft

\begin{tabular}{ccc}
\hline & FITD condition & Control condition \\
\hline Male participants & $76.2 \%(16 / 21)$ & $43.5 \%(10 / 23)$ \\
Female participants & $94.1 \%(16 / 17)$ & $53.3 \%(8 / 15)$ \\
Total & $84.0 \%$ & $47.4 \%$ \\
\hline
\end{tabular}

A 2 (participant gender) $\times 2$ (experimental condition) binary logistic regression was performed using the participants' behavior as the dependent variable. A significant main effect of the experimental condition was reported (Wald $=10.43, p=.001, \operatorname{Exp}(B)=.169 ; 95 \%$ CI $\operatorname{Exp}(B)=.057 ; .497)$ suggesting that significantly more participants intervened in the FITD condition than in the control condition. Neither the main effect of participant gender (Wald $=2.05, p=.152, \operatorname{Exp}(B)=2.077 ; 95 \%$ CI $\operatorname{Exp}(B)=.774 ; 5.650)$ nor the interaction between experimental condition and participant gender (Wald $=1.26, p=.261, \operatorname{Exp}(B)=$ $.517 ; 95 \%$ CI $\operatorname{Exp}(B)=.164 ; 1.633)$ appeared statistically significant.

\section{Discussion}

In this field study, using the intervention to a theft as the dependent variable, we have shown that the FITD technique increased the number of participants who intervened to stop a theft. The effect-size was high $(r=0.362 ; O R=5.93)$, suggesting that using a first request, as in the FITD condition, is a way to increase participants' intervention significantly. The results of this experiment are congruent with previous findings and show that the FITD technique influences behavior.

Additionally, our results show that this technique can influence helping behavior in a situation where there is a risk for the participants. In previous studies on the FITD, the second request was clearly not problematic for the participants because the second request involved asking the participants for a dime (Harris, 1972), or to participate in a survey (Hornik et al., 1991), or to notify someone that he/she has lost something (Uranowitz, 1975; Pascual \& Guéguen, 2004;). Yet another element of interest is added to the literature on commitment in bystander effect (Moriarty, 1975; Shaffer et al., 1975; Harris \& Samerotte, 1976; Stewart \& Cannon, 1977; Schwarz et al., 1980). We have shown that explicit verbal commitment addressed to participants (e.g., "Will you please keep an eye on my things?") is not the only way to influence bystanders' reaction to a theft. In previous studies, the effect of the FITD was the control condition, while in this study, the FITD condition was compared with a control one where no first request was made to the participant. Thus, our findings have considerable theoretical interest.

Harris (1972) and Guéguen and Fischer-Lokou (1999) explained the effect of the FITD neither in terms of self-perception (Freedman \& Fraser, 1966) nor of commitment (Cialdini, 2008; Joule, 1987) but 
with the help of the responsibility norm. According to this norm, performing the first request in the FITD could increase the salience of an individual's perceived responsibility to act. In turn, this feeling would increase the probability that the person would accept the second request. This explanation appears compatible with our findings. In the FITD condition, the first request (i.e., asking for the time) could have activated the salience of the responsibility norm. When the confederate left, this activation was maintained, and when the participants saw that a theft had occurred, they may have deduced that they had a high personal responsibility to intervene.

In a study conducted by Guéguen and Triffaut (2003), a female confederate had initially obtained from participants that they protect her property in her absence. In the control condition, this solicitation had not been made. In both conditions, nothing wrong happened during the confederate's absence. After the confederate's return, she waited several minutes and then left but forgot an object. It was found that more participants warned her that she had left something behind when an initial commitment had been made. Guéguen and Triffaut argued that an activation of responsibility occurred in the commitment condition, and that activation persisted over time, which in turn explains why more participants warned the confederate. A second experiment conducted by these authors confirmed that participants expressed a higher feeling of responsibility toward the confederate in the commitment condition even after the confederate had returned to her place and therefore after the initial commitment had come to an end. Thus, in our experiment, the first request probably activated this feeling of responsibility that persisted during the absence of the confederate and probably created an internal pressure to act when the theft occurred. These results suggest that the feeling of responsibility could be an important theoretical approach in future research on the FITD.

\section{Implication for crime prevention}

The results reported in this study suggest that it is sometimes possible to prevent some crimes in public places, with the help of a simple and appropriate behavior. The single sentence "Will you please keep an eye on my things?" is associated with a dramatic increase of people's reaction to a theft (Moriarty, 1975; Shaffer et al., 1975; Harris \& Samerotte, 1976; Stewart \& Cannon, 1977; Schwarz et al., 1980). Our own study has shown that asking people for the time is sufficient to promote later intervention. Such findings suggest, according to Felson (1995), that everybody can help discourage crime if people are solicited to pay attention to somebody's property or to somebody else. In our study, participants in the FITD condition were just asked for the time; they were not asked to pay attention to the confederate's property as in the previous research on commitment cited in this paper. Such effects suggest, perhaps, that just interacting with unknown individuals is sufficient to activate a "guardianship" effect. We could expect that perhaps a single smile or "hello" addressed to participants might be sufficient to promote later intervention to the theft, and this is an avenue worth exploring in another study. A little show of social interest for people might be sufficient to create "guardians" and to prevent crimes in public places. It would also be worth investigating the behavioral effects associated with such attention in our daily lives, which could be a good way to discourage some crimes in public places.

Limitations and conclusion

This study has some limitations. Only male confederates were used, and the generalization of the findings to female victims and female theft still remains in question. Only reactions to a theft were examined in this study, and the generalization of the FITD to other crimes needs to be examined in future studies. In this study, participants were aged between 20 and 30, but reactions from older individuals could fruitfully be examined. The experiment was conducted in a bar, and we used a random assignment of the participants in the two experimental conditions. However, we did not control individuals for alcohol consumption, and it would be worth investigating whether alcohol consumption is a moderator of intervention to stop the thief.

In conclusion, this study has shown that the FITD technique is not limited to low-cost verbal helping requests and appears effective to increase spontaneous helping behavior associated with a potential high level of risk for participants. For the first time, we have reported that this well-known technique appears effective in crime prevention. Our study findings suggest that the FITD technique could have the property to activate the feeling of individual responsibility of someone toward a stranger; such responsibility explanation is worth exploring in future research studies. 


\section{References}

Beaman, A. L., Cole, M. C., Preston, M., Klentz, B., \& Mehrkens-Steblay, N. (1983). Fifteen years of footin-the-door research: A meta-analysis. Personality and Social Psychology Bulletin, 9, 181-196.

Burger, J. M. (1999). The foot-in-the-door compliance procedure: A multiple-process analysis and review. Personality and Social Psychology Review, 3, 303-325.

Carducci, B. J., Deuser, P. S., Bauer, A., Large, M., \& Ramaekers, M. (1989). An application of the foot-inthe-door to organ donation. Journal of Business \& Psychology, 4, 245-249.

Cialdini, R. (2008). Influence: Science and practice. Boston, MA: Allyn \& Bacon.

Dillard, J. P., Hunter, J. E., \& Burgoon, M. (1984). Sequential-request persuasive strategies: Meta-analysis of foot-in-the-door and door-in-the-face. Human Communication Research, 10, 461-488.

Dolin, D. J., \& Booth-Butterfield, S. (1995). Foot-in-the-door and cancer prevention. Health Communication, 7, 55-66.

Felson, M. (1995). Those who discourage crime. In J. E. Eck \& D. Weisburd (Eds.), In crime and place (pp. 53-66). Monsey, NY: Criminal Justice Press.

Fern, E., Monroe, K., \& Avila, R. (1986). Effectiveness of multiple request strategies: A synthesis of research results. Journal of Marketing Research, 23, 144-152.

Freedman, J. L., \& Fraser, S. C. (1966). Compliance without pressure: The foot-in-the-door technique. Journal of Personality and Social Psychology, 4, 195-202.

Goldman, M., Creason, C. R., \& McCall, C. G. (1981). Compliance employing a two-feet-in-the-door procedure. The Journal of Social Psychology, 114, 259-265.

Guéguen, N., \& Fischer-Lokou, J. (1999). Sequential request strategy: Effect on donor generosity. The Journal of Social Psychology, 139, 669-671.

Guéguen N., \& Jacob, C. (2001). Fund-raising on the Web: The effect of an electronic foot-in-the-door on donation. CyberPsychology and Behavior, 4, 705-709.

Guéguen, N., Marchand, M., Lourel, M., \& Pascual A. (2008). The effect of the foot-in-the-door technique on a courtship request: A field experiment. Psychological Reports, 103, 529-534.

Guéguen, N., Meineri, S., Martin, A., \& Grandjean, I. (2010). The combined effect of the foot-in-the-door technique and the "But you are free" technique: An evaluation on the selective sorting of household wastes. EcoPsychology, 2, 231-237.

Guéguen N., \& Triffaut J. (2003). L'effet de persistance et de transfert d'une requête engageante : Une illustration en milieu naturel. Revue Internationale de Psychologie Sociale, 15, 5-28.

Harris, M. B. (1972). The effects of performing one altruistic act on the likelihood of performing another. The Journal of Social Psychology, 88, 65-73.

Harris, M., \& Samerotte, G. (1976). The effects of actual and attempted theft, need, and a previous favor on altruism. The Journal of Social Psychology, 99, 193-202.

Hornik, J., Zaig, T., \& Shadmon, D. (1991). Reducing refusals in telephone surveys on sensitive topics. Journal of Advertising Research, 31, 49-56.

Joule, R.-V. (1987). Le pied-dans-la-porte: Un paradigme à la recherche d'une théorie. Psychologie Française, 32, 301-306.

Katzev, R. D., \& Johnson, T. R. (1983). A social-psychological analysis of residential electricity consumption: The impact of minimal justification techniques. Journal of Economic Psychology, 3, 267-284.

Kiesler, C. A. (1971). The psychology of commitment: Experiments linking behavior to belief. New York, NY: Academic Press.

Moriarty, T. (1975). Crime, commitment and the responsive bystander: Two field experiments. Journal of Personality and Social Psychology, 31, 370-376.

Pascual, A., \& Guéguen, N. (2004). Cultural differences in altruistic behavior: Quasi replication of Uranowitz's foot-in-the-door with implicit demand. Psychological Reports, 94, 767-770.

Pascual, A., \& Guéguen, N. (2005). Foot-in-the-door and door-in-the-face: A comparative meta-analytic study. Psychological Reports, 96, 122-128.

Schwarz, L., Jennings, K., Petrillo, J., \& Kidd, R. (1980). Role of commitments in the decision to stop a theft. The Journal of Social Psychology, 110, 183-192. 
Shaffer, D., Rogel, M., \& Hendrick, C. (1975) Intervention in the library: The effect of increased responsibility on bystanders' willingness to prevent a theft. Journal of Applied Social Psychology, 5, 303-319.

Stewart, J., \& Cannon, D. (1977). Effects of perpetrator status and bystander commitment on responses to a simulated crime. Journal of Police Science and Administration, 5, 318-323.

Uranowitz, S. (1975). Helping and self-attributions: A field experiment. Journal of Personality and Social Psychology, 31, 852-854. 